Power, W. and Taylor, D. (2019). "Last Planner ${ }^{\circledR}$ System and Planned Percent Complete: An Examination of Individual Trade Performances." In: Proc. $27^{\text {th }}$ Annual Conference of the International. Group for Lean Construction (IGLC), Pasquire C. and Hamzeh F.R. (ed.), Dublin, Ireland, pp. 1 - 12. DOI: https://doi.org/10.24928/2019/0164 . Available at: 〈www.IGLC.net>.

\title{
LAST PLANNER® SYSTEM AND PLANNED PERCENT COMPLETE: AN EXAMINATION OF INDIVIDUAL TRADE PERFORMANCES
}

\author{
William Power ${ }^{1}$ and Darrin Taylor ${ }^{2}$.
}

\begin{abstract}
There is a dearth of research on Lean in the Irish construction sector and on the application of Lean thinking and practices on live capital projects. Lean Construction (LC) is recommended as an antidote to productivity issues encountered on capital project delivery. Last Planner ${ }^{\circledR}$ System (LPS) is a key tool of LC, and high Planned Percent Complete (PPC) achievement is positively correlated to increased productivity. This study examines individual trades' differing PPC performances on two overlapping capital projects; it considers explanations for those differences; and it identifies areas for improvement to enhance PPC on future capital projects. LC-driven contractor selection, early trades engagement in the design process, implementation of all functions of LPS, Lean education and training, increased modularisation and prefabrication, and embracing technological advances are posited as areas for focused improvements.
\end{abstract}

\section{KEYWORDS}

Lean Construction, LPS, Collaboration, Workflow, PPC, Mindset, Ireland.

\section{INTRODUCTION}

Upon completion of a part-time executive master's programme in Lean, the lead author has applied Lean thinking and practices within his employer organisation, as well as on its capital projects, and collected data and other information at the gemba as part of ongoing research development in collaboration with his academic partner. This study emanates from the latter applied research on Lean Construction (LC) and Last Planner® System (LPS) on two overlapping EPCMV (Engineering, Procurement, Construction Management, Validation) Projects ("Project A" and "Project B").

\section{BACKGROUND AND CONTEXT}

Construction is a dynamic and critical economic sector globally, however, it struggles to add value to its clients, it remains fundamentally inefficient, and it faces a "productivity imperative" (McKinsey 2017). Other economic sectors have transformed their efficiency

1 Productivity \& Performance Manager, DPS Group, 4 Eastgate Avenue, Eastgate Business Park, Little Island, Co. Cork, Ireland, +353 21 7305000, willie.power@dpsgroupglobal.com

2 Principal Lead, Academy of Lean Enterprise Excellence, RIKON Centre, School of Business, Waterford Institute of Technology, Waterford, Ireland, +353 51 834129, dtaylor@wit.ie 
using Lean (Hines et al. 2018). However, construction productivity has remained stagnant or regressed, and thus the sector has looked to LC as an antidote to the ills of the sector (Koskela 1999) and as a means of delivering the requisite value that clients have been longdemanding (Koskela 1992; Ballard 2000; Hamzeh et al. 2009).

A key concept in LC is the provision of reliable workflow to the teams to reduce uncertainty in the delivery process (Ballard 2000). LPS is a key waste elimination and variability reduction technique that addresses that uncertainty (Hamzeh et al. 2009).

Whilst much has been written on LPS over the past 25 or more years, there appears to be a dearth of research that investigates the performance of individual trade contractors and their respective and collective contributions to the weekly plus overall project PPC. This study explores PPC across two Projects; it examines commonalities and differences between relevant trades' PPC; and it identifies areas of improvement for implementation on future projects.

\section{LITERATURE REVIEW}

\section{LEAN CONSTRUCTION}

Koskela (1992 p.64) challenged the construction sector to apply extant Lean production thinking and practices, positing that Lean '... contains a promise of tremendous possibilities for improvement and of a solution of the chronic problems of construction'. Ballard was at the same time developing what became known as the "Last Planner System of Production Control" (Ballard 2000). Koskela's development of the theory and more holistic approach, alongside Ballard and Howell's tools, extended Lean into construction (Ballard et al. 2007).

Early LC researchers recognised that Traditional Construction Project Management (TCPM) was unable to cope with the increasingly more complex and dynamic projects clients were demanding to be delivered. Construction needed to adopt a productivity mindset, and Koskela's Transformation-Flow-Value (TFV) theory integrated the successful qualities of Craft, Mass, and Lean Production concepts (Abdelhamid and Salem 2005), thus creating a comprehensive theory of production management for construction.

TFV focuses on reducing lead times and minimising variability whilst simplifying onsite and off-site processes (Koskela 1992). TFV also promotes pull concepts and continuous improvement of the delivery process (Koskela 1999). The value view of TFV theory considers voice of customer (VOC) by emphasising delivery of what is considered valuable from the customer's, and crucially the next-customer's, viewpoint (Koskela 2000; Ballard et al. 2007).

Accordingly, specific tools were developed for LC, namely Target Value Design (TVD), the Lean Project Delivery System (LPDS), and LPS (Howell and Koskela 2000).

\section{LAST PlanNeR@ SYSTEM}

LPS is central to the implementation of LC and requires continuous and collaborative effort from all stakeholders in a production planning and control system to reduce variability whilst enhancing reliability and predictability in construction workflows (Hamzeh and Bergstrom 2010; Howell et al. 2010). This differs to the TCPM approach of directing and 
adjusting after the occurrence (Koskela and Howell 2002) and the assumption that variability in workflow lies outside the control of management.

LPS was developed from research into productivity improvement, with Ballard and Tommelein (2016 p.59) positing that 'the inspiration for LPS was the discovery of chronically low workflow reliability in construction projects'. Ballard et al. (2009) summarise the 'principles' underlying LPS as follows:

i. Plan in greater detail as you get closer to doing the work.

ii. Produce plans collaboratively with those who will do the work.

iii. Reveal and remove constraints on planned tasks as a team.

iv. Make and secure reliable promises.

v. Learn from breakdowns.

There is a dearth of research on LPS vis-à-vis how each trade contributes towards the overall PPC which measures the percentage of tasks completed relative to those planned. However, Ballard and Tommelein (2016 p.60) assert that '...from the perspective of continuous improvement, LPS's job is to stabilise operations so they can be further improved, both individually and in the processes which they comprise, but it also improves productivity. Many, perhaps most, people are satisfied with that and don't exploit the opportunity for more fundamental improvement in performance'.

PPC is a key metric of LPS and measures workflow reliability - a high PPC indicates a well-planned production process with tasks screened in advance, ensuring high workflow reliability between teams (Ballard 2000). However, Ballard and Tommelein (2016 p.59) warn against placing too much focus on PPC figures, stating '...PPC could be $100 \%$, productivity excellent, and a project still be falling behind schedule'. This emphasises the importance of using all functions of LPS to ensure PPC and productivity are linked to the overall milestone schedule (Hamzeh et al. 2009). As PPC is positively linked to productivity (Liu et al. 2010), it is critical for LPS users to ensure that the trades teams executing the work are afforded the greatest opportunity of achieving high PPC.

Howell and Ballard (1994) advise reducing workflow variation by stabilising all functions through which work flows, from concept to completion. Whilst Hamzeh et al. (2009) posit formalising the planning and production operations process on the construction project. Ensuring consideration of the eight prerequisite flows (Koskela 2000; Pasquire and Court 2013) to make the right tasks sound is an essential element of LPS: 'Progress rises and falls with PPC to the extent that tasks are made ready in the right sequence and rate' (Ballard and Tommelein 2016 p.60).

Understanding the Reasons for Non-Completion (RNC) of tasks will enable future improvement of the planning process (Liu et al. 2010) as it provides teams with trends which can be used to develop strategies to prevent re-occurrence of the same failures in the future (Ballard and Tommelein 2016).

\section{METHODOLOGY}

Mixed-methods were adopted encompassing a critical literature review, site documentation data-analysis, focus groups, and semi-structured purposeful interviews (Creswell 2013). The first author acted as lead researcher in his capacity as LPS Facilitator on both Projects. 
The mixed-methods approach helped to minimise bias as both the quantitative and qualitative models have individual weaknesses which can be compensated by the comparative strengths of the other methods (Steckler et al. 1992) and such triangulation enhances the depth, quality, and validity of the research findings (Bogdan and Biklen 2006).

A sequential explanatory approach (Creswell 2009) was utilised, with the quantitative data being collected weekly as the Projects proceeded and the qualitative data being gathered after Projects were completed. As per Creswell et al. (2003), priority was given to the quantitative data as this was analysed and then connected to the next stage by selection of methods and participants best-suited for the follow-up qualitative data collection phase (Creswell 2009). The analysis of the data informed the secondary data collection process (Creswell 2009) which is useful when unexpected results arise from a quantitative study (Morse 2003).

Table 1 provides an overview of the three focus groups which comprised site construction management team (CMT), trades' Last Planners, and senior operations management; as well as the purposeful sample of seven interviewees representing senior management of the key trades contractors.

Table 1: Qualitative Research Sources

\begin{tabular}{ll}
\hline Source & Project \& Participants \\
\hline Focus Group 1 & Project A (n6) - CMT (2); Trades Last Planners (3); Director \\
Focus Group 2 & Project B (n7) - CMT (4); Trades Last Planners (3) \\
Interviewee A & Project A - Mechanical (M) \& Electrical (E) Project Manager \\
Interviewee B & Project A - Civil, Structural \& Architectural Project Manager \\
Interviewee C & Project A - Cleanroom Project Manager \\
Interviewee D & Project B - Mechanical Project Manager \\
Interviewee E & Project B - Electrical Project Manager \\
Interviewee F & Project B - Civil, Structural, \& Architectural Director \\
Interviewee G & Project B - Cleanroom Project Manager \\
Focus Group 3 & Projects A \& B (n7) - Senior Operations Management \\
\hline
\end{tabular}

Unique sources were sought to increase validity and to provide a wider perspective. Focus group sessions were conducted on both Projects to gather the opinions of the trades' Last Planners on the challenges and opportunities for improvement in LPS implementation. The qualitative findings were transcribed, then analysed using a thematic analysis approach and organised into different themes (Braun and Clarke 2006). Inferences drawn from the emerging themes were checked by triangulation against the literature review findings to check their reliability and integrity (Steckler et al. 1992). In accordance with Creswell (2009), the research is presented as two distinct findings sets, with the quantitative findings directing the qualitative research.

The following research questions were posed:

1. What differences exist between individual trades' PPC?

2. How can these differences be explained? 
3. What areas of improvement can be implemented on future projects to enhance $P P C$ ?

\section{FINDINGS}

In summary, data in the form of PPC and RNC was collected weekly on both Projects, accumulating to 69 weeks of data for Project A and 58 weeks of data for Project B.

\section{QUESTION 1: WHAT DIFFERENCES EXIST BETWEEN INDIVIDUAL TRADES' PPC?}

To address question 1, we examined the quantitative PPC data that was retained on both Projects for the duration of each trade's presence, and their average PPC is presented in Table 2.

On Project A, there was a noticeable gap in the average PPC between the CSA, Steel/Roofing/Cladding, and Cleanroom trades on one end, and the M\&E and Sprinkler trades on the other end. CSA were on site for almost twice the duration of other trades and they committed $43 \%$ of the work tasks to the weekly work plan (WWP). Steel/Roofing/Cladding, despite completing only $15 \%$ of the work tasks, achieved $80 \%$ PPC. M\&E and Sprinkler, achieved 91-92\% PPC each on a combined $40 \%$ of the work tasks. It is noteworthy that the M\&E company and Sprinkler company on Project A were knowledgeable and practiced in LC.

Similar gaps were evident on Project B. The CSA were longest on site, completing 29\% of tasks and achieving $80 \%$ PPC. Mechanical (90\%) and Electrical (89\%) were the highest PPC achievers with $23 \%$ and $22 \%$, respectively, of total tasks committed to the work plan. The M\&E companies on Project B (different to that on Project A) were also knowledgeable and practiced in LC. However, the Sprinkler company on Project B - a locally-based incumbent contractor - had a poorer PPC performance, and it is noteworthy that it was neither knowledgeable nor practiced in LC.

Table 2: Individual Trades' Duration on Projects and Average PPC

\begin{tabular}{lllllll}
\hline & \multicolumn{2}{l}{ Project A } & \multicolumn{3}{c}{ Project B } \\
\cline { 2 - 7 } Trades & $\begin{array}{l}\text { Weeks } \\
\text { on } \\
\text { Project }\end{array}$ & $\begin{array}{l}\text { Averag } \\
\text { e PPC }\end{array}$ & $\begin{array}{l}\text { Per Cent } \\
\text { of Total } \\
\text { Project } \\
\text { Tasks }\end{array}$ & $\begin{array}{l}\text { Weeks on } \\
\text { Project }\end{array}$ & $\begin{array}{l}\text { Average } \\
\text { PPC }\end{array}$ & $\begin{array}{l}\text { Per Cent } \\
\text { of Total } \\
\text { Project } \\
\text { Tasks }\end{array}$ \\
\hline CSA & 69 & $84 \%$ & $43 \%$ & 58 & $80 \%$ & $29 \%$ \\
\hline Cleanroom & 27 & $86 \%$ & $2 \%$ & 54 & $84 \%$ & $22 \%$ \\
\hline Steel/Roofing/Cladding & 54 & $80 \%$ & $15 \%$ & 45 & $72 \%$ & $2 \%$ \\
\hline Mechanical & 34 & $92 \%$ & $15 \%$ & 54 & $90 \%$ & $23 \%$ \\
\hline Electrical & 34 & $92 \%$ & $21 \%$ & 50 & $89 \%$ & $22 \%$ \\
\hline Sprinkler & 40 & $91 \%$ & $4 \%$ & 46 & $79 \%$ & $2 \%$ \\
\hline
\end{tabular}

In accordance with the sequential explanatory design strategy (Creswell, 2009) the key findings arising from the quantitative research are presented in Table 3. 
Table 3: Summary of Key Quantitative Findings

\begin{tabular}{|c|c|}
\hline Themes & Findings \\
\hline \multirow[t]{5}{*}{$\begin{array}{l}\text { Trade Contractor } \\
\text { PPC }\end{array}$} & $\begin{array}{l}\text { - M\&E (different contractors on both Projects) achieved the higher PPC on } \\
\text { both Projects A and B. }\end{array}$ \\
\hline & $\begin{array}{l}\text { - Sprinkler (different contractors on both Projects) achieved a high PPC on } \\
\text { Project A and a lower PPC on Project B. }\end{array}$ \\
\hline & $\begin{array}{l}\text { - CSA (different contractors on both Projects) achieved a lower PPC than } \\
\text { M\&E on each Project. }\end{array}$ \\
\hline & $\begin{array}{l}\text { - Cleanroom (different contractors on both Projects) achieved a lower PPC } \\
\text { than M\&E on each Project. }\end{array}$ \\
\hline & $\begin{array}{l}\text { - Steel/Roofing/Cladding (different contractors on both Projects) achieved } \\
\text { the lowest PPC on each Project. }\end{array}$ \\
\hline \multirow[t]{5}{*}{ PPC ranges } & - M\&E ranged between $92 \%$ and $89 \%$. \\
\hline & - CSA ranged from $84 \%$ to $80 \%$. \\
\hline & - Cleanroom ranged from $86 \%$ to $84 \%$. \\
\hline & - Steel/Roofing/Cladding ranged more widely from $80 \%$ to $72 \%$. \\
\hline & - Sprinkler had the greatest range from $91 \%$ to $79 \%$. \\
\hline RNC & $\begin{array}{l}\text { On both Projects, "schedule/coordination", "resource availability", and } \\
\text { "prerequisite work by others" were the top three RNC. }\end{array}$ \\
\hline
\end{tabular}

An analysis of the findings from the quantitative element of the study generated key points to take forward to the focus groups and semi-structured purposeful interviews.

\section{QUESTION 2: HOW CAN THESE DIFFERENCES BE EXPLAINED?}

As the quantitative research analysis determined a gap existed between individual trades' PPC, we proceeded to conduct focus groups and interviews as we sought to address this question. Two focus group sessions were conducted with the trades' Last Planners and members of the CMT from both Project A and Project B, and the key findings from those focus groups are presented in Table 4 . We next combined the findings from those focus group sessions with the quantitative data findings and our analysis of pertinent literature, and this provided the basis for a deeper and more nuanced assessment to bring forward into the interviews (Table 5).

The M\&E trades clearly performed the best on both Projects - with various companies providing the Mechanical and the Electrical services on each Project, and these companies being early adopters and practitioners of LC. Interestingly, the Electrical company on Project B also provided the Sprinkler services on Project A, which performed substantially better than the Sprinkler company on Project B which is not a practitioner of LC.

It is therefore our assessment that embedded LC knowledge and proven LPDS and LPS practice is the primary explanation for the differences in PPC experienced on both Projects studied.

Table 4: Key Focus Group Findings

Themes Findings




\begin{tabular}{ll}
$\begin{array}{l}\text { Time required } \\
\text { for, and } \\
\text { commitment to, } \\
\text { LPS }\end{array}$ & $\begin{array}{l}\text { Lack of adequate trade management time to adequately plan WWP. No } \\
\text { dedicated and trained Last Planner management resource. }\end{array}$ \\
$\begin{array}{l}\text { Late receipt of } \\
\text { WWP from } \\
\text { trades }\end{array}$ & $\begin{array}{l}\text { Much greater coordination is needed where trades overlap and late receipt of } \\
\text { WWPs left little time for CMT supervision to proof and coordinate the plan. }\end{array}$ \\
$\begin{array}{l}\text { Specialist } \\
\text { resource } \\
\text { availability }\end{array}$ & $\begin{array}{l}\text { The local region is currently experiencing a construction boom in the Pharma } \\
\text { sector, and availability of specialist resources was a major challenge for clients } \\
\text { and management teams. }\end{array}$ \\
$\begin{array}{l}\text { Not using all } \\
\text { functions of LPS }\end{array}$ & $\begin{array}{l}\text { Inconsistency of implementation of all functions of LPS. Project A successfully } \\
\text { implemented all functions of LPS, while Project B experienced implementation } \\
\text { issues due to its size and complexity. }\end{array}$ \\
$\begin{array}{l}\text { Incomplete design led to delays in resolving design-related constraints. Delayed } \\
\text { issues }\end{array}$ & $\begin{array}{l}\text { appointment of trades meant a lack of trade involvement in early planning, } \\
\text { scheduling, and design coordination decisions. }\end{array}$ \\
\hline
\end{tabular}

The key interview findings are presented in Table 5.

Table 5: Key Interview Findings

\begin{tabular}{|c|c|}
\hline Interviewees & Findings \\
\hline A B C E F G & $\begin{array}{l}\text { M\&E adopt a productivity-based and metrics-focused approach and mindset to } \\
\text { construction delivery. CSA approach is more reactionary, with an acceptance of } \\
\text { the peculiarities and traditional problems associated with construction work } \\
\text { execution. }\end{array}$ \\
\hline$A \subset E G$ & $\begin{array}{l}\text { The LC-practiced M\&E contractors have developed management systems and } \\
\text { structures enabling them to set their own agenda on a project, and they lead out } \\
\text { their own design, schedule, and workflows. CSA appear to be under-resourced at } \\
\text { site management level with immediate problem-solving prioritised over short- to } \\
\text { medium-term planning. }\end{array}$ \\
\hline A B C D E F G & $\begin{array}{l}\text { Late and incomplete design, as well as contractors commencing on site in } \\
\text { advance of design being sufficiently developed, had an impact on the smooth flow } \\
\text { of work tasks. Early engagement of the M\&E contractors in the design } \\
\text { development process was considered a key advantage in maintaining reliable } \\
\text { flow and contributing to higher PPC. }\end{array}$ \\
\hline$A B C G$ & $\begin{array}{l}\text { Engagement with, and preparation for the LPS process, as well as using all } \\
\text { functions of the system, is critical for successful project delivery. Poor lookaheads } \\
\text { lead to inadequate preparation of workplans, resulting in missed tasks being } \\
\text { categorised as 'schedule/coordination' and 'prerequisite work by others', } \\
\text { impacting on other trades' PPC. }\end{array}$ \\
\hline A B D E G & $\begin{array}{l}\text { Prefabrication and Modularisation offers distinct advantages by reducing onsite } \\
\text { activities and the associated coordination issues. }\end{array}$ \\
\hline A C D E G & $\begin{array}{l}\text { The embracing of ICT advancements in construction software, allied to the } \\
\text { utilisation of handheld applications and devices, enables more efficient solutions } \\
\text { to data storage and acquisition. }\end{array}$ \\
\hline
\end{tabular}

\section{QUESTION 3: WHAT AREAS OF IMPROVEMENT CAN BE IMPLEMENTED ON FUTURE PROJECTS TO ENHANCE PPC?}

A final focus group session involving EPCMV senior operations management was held to discuss and validate the research findings, and to identify areas for improvement that could 
be implemented on future projects to enhance individual trades' PPC as well as the overall project PPC. Table 6 presents those identified areas for improvement.

Table 6: Areas of Improvement for Implementation on Future Projects

\begin{tabular}{|c|c|}
\hline Areas & Findings \\
\hline Procurement & $\begin{array}{l}\text { Feature LC in prequalifications, tenders, and actual contracts. Contractor selection } \\
\text { needs to be restricted to proven LC companies. Ongoing assessment systems should } \\
\text { incentivise process excellence and continuous improvement. }\end{array}$ \\
\hline $\begin{array}{l}\text { Trades' } \\
\text { Differences }\end{array}$ & $\begin{array}{l}\text { Provide greater attention and involvement at design stage for CSA, } \\
\text { Steel/Roofing/Cladding, and Cleanroom. Review contracting strategy to } \\
\text { accommodate early appointment and involvement of these trades as early as } \\
\text { possible, and engage them across the design process. No contractor should be } \\
\text { permitted to commence on site without a clearly defined and agreed design in place. } \\
\text { Develop a trust-driven, transparent, collaborative relationship amongst parties at } \\
\text { design stage. }\end{array}$ \\
\hline $\begin{array}{l}\text { LC Training \& } \\
\text { Education }\end{array}$ & $\begin{array}{l}\text { Deliver LC training and education to the client, the EPCMV team, and contractors to } \\
\text { ensure a productivity-based and metrics-focused mindset is embedded amongst the } \\
\text { construction delivery partners. }\end{array}$ \\
\hline $\begin{array}{l}\text { LPS Training } \\
\text { \& Education }\end{array}$ & $\begin{array}{l}\text { Schedule more detailed LPS training and refresher courses into the project duration } \\
\text { and have these supported by the client. Focus to be placed on enabling flow with the } \\
\text { Tasks Made Ready (TMR) metric and the creation of sound, constraint-free tasks } \\
\text { ahead of committing them to the WWPS. }\end{array}$ \\
\hline Off-Site & $\begin{array}{l}\text { Demand more off-site fabrication and assembly processes. Contractors should } \\
\text { propose a greater variety of options, and clients should ensure modularisation is } \\
\text { respected to avoid requirement for bespoke solutions. }\end{array}$ \\
\hline ICT & $\begin{array}{l}\text { Adopt site-wide technological solutions across all contractors to improve visualisation } \\
\text { (BIM), process improvement (RFIs, punch-lists, submittals), planning and } \\
\text { coordination (LPS software), and the efficient accessibility of project documentation } \\
\text { (cloud-based platforms). }\end{array}$ \\
\hline
\end{tabular}

\section{DISCUSSION}

\section{LEAN CONSTRUCTION COMPANIES ARE TOP PERFORMERS}

The better performing trades contractors - the highest PPC achievers - are knowledgeable and practiced early adopters of LC. To assure high performance, the prequalification and selection processes should focus on a contractor's LPDS ability as opposed to lowest cost criteria which can promote loss of value (Sarhan et al. 2017). Client alignment on this point is critical. In this study, the approach of M\&E contractors was productivity-based, and founded on systems and processes that ensured resources and materials were matched with sound, constraint-free tasks prior to commitment to a WWP. That "productivity mindset" understands that creation of even and reliable workflow is critical to improving construction productivity (Ballard et al. 2007; Liu et al. 2010). Efficiency Ratio metrics are a key driver of forward planning, and a measurement of output and productivity at both task and project level within these M\&E companies. However, Howell et al. (2010) assert that such traditional metrics reduce the reliability of workflow by creating a focus on local productivity and executing work out of sequence. It is therefore important that a contract that encourages the dissolution of traditional silos and promotes a more collaborative organisational structure be considered. 


\section{MANAGEMENT RESOURCING}

The findings indicate sufficiently-resourced site management teams and more clearly defined roles amongst the M\&E companies. CSA appear to underestimate the level of management required to support both CMT and client reporting and supervisory requirements. With increasingly tighter margins due to more competitive tendering processes, CSA management and supervision staffing levels are minimised, thus contributing towards a cycle of insufficient planning and coordination and missed tasks (Howell et al. 2010). M\&E primarily have their own direct labour and very few subcontractors, whereas CSA differed in having minimal direct labour and many subcontractors, contributing to greater fragmentation and difficulty of communication on the Projects. The study contends that clients and EPCMV should recognise that CSA requires more attention at both the $\mathrm{E}$ and the $\mathrm{CM}$ stages.

\section{EARLY CONTRACTOR ENGAGEMENT}

$M \& E$ were engaged early and involved in the design coordination and completion of the BIM model on each Project. However, the other trades were pressured to commence on site whilst the design was incomplete, which proved to be a constant constraint throughout the delivery phase of both Projects. Early engagement of key contractors is a critical enabler of LPDS (Ballard et al. 2007) and this study suggests early engagement of all trades in the design process would contribute towards raising their respective PPC whilst lessening any negative impact on other trades and the project overall.

\section{LEAN EDUCATION \& TRAINING}

This study earlier referred to the productivity-based mindset of M\&E, and we suggest investment in Lean education and training would contribute towards developing a value and next-customer awareness amongst the entire project team. M\&E have supervision or charge-hands assigned to specific measurable tasks and are metrics-driven in their planning and setting of outputs and targets. By comparison, CSA appear to thrive on fire-fighting, reactionary problem-solving, and using their creativity to work around constant impending issues, like the improvisation referred to by Hamzeh et al. (2016). The introduction of standard work for trades' management, as well as incorporating the LPS weekly cycle into their working week, is considered a key step towards regularising how trades should approach their work planning and coordination.

\section{LPS ALIGNMENT}

M\&E put more preparation into their weekly planning, and they arrived at the LPS coordination meetings fully prepared and familiar with their scope, whereas CSA were reluctant participants with the LPS process on both Projects. We suggest a more complete implementation of LPS is called for as there is evidence of each trade seeking to maximise their own weekly PPC figures with an absence of consideration for the whole project's gain. CSA's observed constant firefighting left inadequate time for organising and coordinating the flow of work tasks, and that mindset allows little room for effective planning or improvement (Ballard 2000). 


\section{Prefabrication \& Modularisation}

Because of early engagement, much of the mechanical work scope was prefabricated offsite, with site work primarily just an assembly process. Electrical switch-rooms and panels were also fabricated off-site, resulting in installation and connection tasks for the on-site crews. Cleanrooms work on a modular system and, to create the required efficiency, modularisation must be respected and not turned into a bespoke-modular system. CSA work was exclusively site-based transformation of inputs. The amount of variability encountered from resource constraints, poor coordination, late materials ordering, and inadequately screened design, all gave little respite from resolving crises and issues common problems accruing from inadequate lookahead planning (Hamzeh et al. 2012).

\section{TECHNOLOGY OPTIMISATION}

M\&E embraced technological advances, and this contrasted with the CSA contractors on both Projects. M\&E utilised iPads to view the BIM model and isometric drawings in the field, thus increasing visualisation and understanding for the craft workers undertaking the installation. M\&E also utilised cloud-based applications for punch-list identification, monitoring, and closeout. Cleanroom used similar technological aids; however, they highlighted issues relating to incomplete design as well as departures from modularisation impacting on the benefits. CSA only minimally-adopted available construction-based technological assistance. McKinsey (2017 p. 10) suggest the '...biggest barriers to innovation by construction companies are underinvestment in IT and technology more broadly, and a lack of R\&D processes'.

\section{CONCLUSION \& RECOMMENDATIONS}

LC contractors deliver better PPC performances than non-LC contractors. Clients and EPCMV companies should select LC contractors and should use alternative contracting strategies like IPD and relational forms of contract like Integrated Form of Agreement (IFOA) to encourage more widespread use of collaborative working practices. This would help eliminate the siloed approach amongst project parties towards LPS implementation, and embed a "project-first" mindset that aligns project team shared goals with the outcomes valued by the client. Such strategies would also contribute towards resolving many of the issues raised in this study, in particular early appointment and engagement of all parties in the design process. Introducing LPDS requires cultural change (Ballard 2008) and the ensuing LC and LPS education and training would assist in embedding the "Lean mindset" across project participants (Pasquire et al. 2015), allowing for more complete implementation of LC tools like LPS and TVD. Clients and EPCMV companies should encourage the use of prefabrication and modularisation while respecting the prerequisites required to achieve the efficiencies offered. A more holistic adoption of advanced ICTbased applications and platforms should be utilised. Finally, future research is recommended to investigate the obstacles and barriers restricting a more complete adoption of LPS on projects, as well as the wider utilisation of collaborative forms of contracting. 


\section{REFERENCES}

Abdelhamid, T. and Salem, S. (2005) "Lean Construction: A New Paradigm for Managing Construction Projects", International Workshop on Innovations in Materials and Design of Civil Infrastructure, Cairo, Egypt, pp.1-25.

Ballard, G. (2000) The Last Planner System of Production Control, Doctoral Dissertation, The University of Birmingham.

Ballard, G., Kim, Y., Liu, M. and Jang, J. (2007) Roadmap for Lean Implementation at the Project Level, The Construction Industry Institute.

Ballard, G., Hammond, J. and Nickerson, R. (2009) "Production Control Principles", In Proceedings of the 17th annual conference of the International Group for Lean Construction, pp.489-500.

Ballard, G. and Tommelein, I. (2016) "Current Process Benchmark for the Last Planner® System" Lean Construction Journal, pp.57-89.

Bogdan, R.C. and Biklen, S.K. (2006). Qualitative Research in Education: An Introduction to Theory and Methods, Boston: Allyn and Bacon.

Braun, V. and Clarke, V. (2006) "Using thematic analysis in psychology", Qualitative Research in Psychology, 3(2), pp.77-101.

Creswell, J. (2009) Research Design: Qualitative, Quantitative, and Mixed Methods Approaches. London: SAGE Publications.

Creswell, J. (2013) "Steps in Conducting a Scholarly Mixed Methods Study", DBER Speaker Series, Paper 48.

Creswell, J., Plano Clark, V., Gutmann, M. and Hanson, W. (2003) "Advanced Mixed Methods Research Designs", Handbook of Mixed Methods in Social and Behavioral Research, pp.209-240.

Hamzeh, F., Ballard, G., and Tommelein, I.D. (2009) "Is the Last Planner System applicable to design? A case study", In Proceedings of the 17th International Group for Lean Construction Conference, pp.167-176.

Hamzeh, F. and Bergstrom, E. (2010) "The Lean Transformation: A Framework for Successful Implementation of the Last Planner System in Construction", In International Proceedings of the 46th Annual Conference. Associated Schools of Construction.

Hamzeh, F., Ballard, G. and Tommelein, I.D. (2012) "Rethinking Lookahead Planning to Optimize Construction Workflow”, Lean Construction Journal, pp.15-34.

Hamzeh, F., Kallassy, J., Lahoud, M., and Azar, R. (2016). "The First Extensive Implementation of Lean and LPS in Lebanon: Results and Reflections." In Proceedings of the 24th International Group for Lean Construction Conference, pp.33-42.

Hines. P., Taylor, D., and Walsh, A. (2018) "The Lean journey: have we got it wrong?", Total Quality Management \& Business Excellence, DOI: 10.1080/14783363.2018.1429258

Howell, G. and Ballard, G. (1994) "Implementing Lean Construction: Reducing Inflow Variation", In Proceedings of the 2nd International Group for Lean Construction Conference, pp.1-8. 
Howell, G.A. and Koskela, L.J. (2000) "Reforming Project Management: The Role of Lean Construction", In Proceedings of the 8th International Group for Lean Construction Conference, pp.1-10.

Howell, G.A., Ballard, G., and Tommelein, I. (2010) "Construction EngineeringReinvigorating the Discipline", Journal of Construction Engineering and Management, 137(10), pp.740-744.

Koskela, L. (1992) Application of the New Production Philosophy to Construction, (No. 72), Stanford, CA: Stanford University.

Koskela, L.J. (1999) "Management of production in construction: A theoretical view". In Proceedings of the 7th International Group for Lean Construction Conference, pp.241252.

Koskela, L. (2000) An Exploration Towards a Production Theory and Its Application to Construction. VTT Technical Research Centre of Finland.

Koskela, L. and Howell, G.A. (2002) "The Underlying Theory of Project Management is Obsolete", In Proceedings of the PMI Research Conference, pp.293-302.

Liu, M., Ballard, G. and Ibbs, W. (2010) "Work Flow Variation and Labor Productivity: Case Study", Journal of Management in Engineering, 27(4), pp.236-242.

McKinsey and Company (2017) Reinventing Construction: A Route to Higher Productivity, McKinsey Global Institute, [Online] Available at www.mckinsey.com/industries/capital-projects-and-infrastructure/ourinsights/reinventing-construction-through-a-productivity-revolution (Accessed 31 January 2019).

Morse, J. (2003) "Principles of Mixed Methods and Multimethod Research Design", Handbook of Mixed Methods in Social and Behavioral Research, 1, pp.189-208.

Pasquire, C. and Court, P. (2013) "An Exploration of Knowledge and Understanding - The Eighth Flow", In Proceedings of the 21st International Group for Lean Construction Conference, pp.1-10.

Pasquire, C., Daniel, E., and Dickens, G. (2015) 'Scoping Study to define a major research project investigating the implementation of Last Planner System, Collaborative Planning and Collaborative Working in the UK Road Transport Sector including identifying funding sources', Final Report, Centre for Lean Projects, Nottingham Trent University, UK. [Online] Available at http://assets.highways.gov.uk/specialistinformation/knowledge-compendium/2014-2015/Snapshot+Final+Report.pdf (Accessed 02 February 2019).

Steckler, A, McLeroy, K, Goodman, R, Bird, S, and McCormick, L. (1992) "Towards Integrating Qualitative and Quantitative Methods: An Introduction", Health Education Quarterly, 19(1), pp.1-8. 